\title{
Influence of Deformation Parameters on Fracture Mechanism of Ti40 Titanium Alloy
}

\author{
Zhu Yancun ${ }^{1,2}, \quad$ Zeng Weidong ${ }^{2}, \quad$ Zhao Yongqing ${ }^{3}$ \\ ${ }^{1}$ Shanxi Provincial Key Laboratory of Metallurgical Device Design Theory and Technology, Taiyuan University of Science and Technology, \\ Taiyuan 030024, China; ${ }^{2}$ State Key Laboratory of Solidification Processing, Northwestern Polytechnical University, Xi'an 710072, China; \\ ${ }^{3}$ Northwest Institute for Nonferrous Metal Research, Xi'an 710076, China
}

\begin{abstract}
An important concern in forming is whether the desired deformation can be accomplished without cracking or fracture of the work material. In this research, based on the cracking specimens obtained from hot compression experiment, the fracture behavior of as-cast highly $\beta$ stabilized Ti40 alloy was investigated at the deformation temperatures of 1123 1373 K, strain rates of $0.01 \sim 10 \mathrm{~s}^{-1}$ and height reduction of $70 \%$. The main fracture modes consist of $45^{\circ}$ shear fracture and longitudinal cracking occurring on free-surface, as well as inner cracking occurring at the triple boundary junctions. Moreover, the influence of deformation parameters on fracture mechanism was analyzed emphatically in terms of SEM. At low temperature of $1123 \mathrm{~K}$ the transgranular cleavage brittle fracture is observed; at $1273 \mathrm{~K}$ the ductile fracture occurs; at high temperature of $1373 \mathrm{~K}$ a lot of small dimples on the fracture interface are examined. Furthermore, the effect of strain rate on the fracture behavior of as-cast Ti40 alloy is significant. At $0.01 \mathrm{~s}^{-1}$, the fracture des not occur. At the strain rates of 0.1 and $1 \mathrm{~s}^{-1}$, the fracture surface is covered with a large amount of dimples indicating that the fracture mode is ductile fracture, while at high strain rate of $10 \mathrm{~s}^{-1}$, the fracture surface shows a brittle fracture feature. Finally, the damage mechanism and fracture reason were discussed and fracture principle diagram was drawn for the as-cast Ti40 titanium alloy.
\end{abstract}

Key words: Ti40 titanium alloy; deformation parameters; fracture mechanism

Workability can be defined as the degree of deformation that can be achieved in a particular metalworking process without creating an undesirable condition, such as cracking or fracture $^{[1]}$. Material workability directly affects its application and finished product ratio. In recent years, increasing attention has been received with respect to the fracture behavior and damage mechanism by many material scientists. Therefore, systematic analysis and in-depth discussion on the damage mechanism and fracture reason of materials were very necessary. Kiran and Khandelwal ${ }^{[2]}$ proposed a coupled microvoid elongation and dilation based continuum damage model for structural steels and pointed out that the damage evolution in this model is derived from micromechanical analyses. Katani et al. ${ }^{[3]}$ found the main controlling behavior to forming a particular number of micro-voids just before cracking mainly at $\alpha$ side near the $\alpha / \beta$ boundary followed by shear fracture between them for ductile cracking of Ti-6Al-4V. Boutarek et al. ${ }^{[4]}$ studied the characterization and examination of the fracture mechanisms acting simultaneously on the fractured surface of a nickel-based Inconel 713 superalloy gas turbine blade and found that the main fracture mechanism is intergranular thermo-mechanical fatigue starting at the border of the blade. Semiatin et al. ${ }^{[5]}$ established the occurrence of free-surface fracture during subtransus hot pancake forging of Ti-6Al-4V and pointed out that the free-surface fracture is attributed to cavity initiation near surface. Calcagnotto et al. ${ }^{[6]}$ researched the fracture mechanisms in fine- and ultrafinegrained ferrite/martensite dual-phase steels and pointed out

Received date: May 18, 2016

Foundation item: National Natural Science Foundation of China (51501122, 51075333); Research Fund for the Doctoral Program of Higher Education of China (20132016); Jincheng Science and Technology Plan Project (201501004-8)

Corresponding author: Zhu Yanchun, Ph. D., College of Mechanical Engineering, Taiyuan University of Science and Technology, Taiyuan 030024, P. R. China, Tel 0086-351-6998115, E-mail: 1zlzyc@163.com 
that the grain refinement promotes ductile fracture mechanisms. Obviously, these significant researches well promoted the development of damage and fracture mechanism of materials.

Titanium alloys have been extensively used in advanced aero-engines due to a unique combination of properties such as high strength and toughness, low density, good corrosion resistance, and excellent high-temperature properties ${ }^{[7,8]}$. However, the major drawback for titanium alloys is their high cost or, at least, extreme cost fluctuation that is why the design should be performed with high accuracy for minimal loss ${ }^{[3,9]}$. Thus the study on the fracture behavior and mechanism of titanium alloys is very significant for the engineering application of titanium alloys. In the present paper, the researched material is Ti40 titanium alloy, which is a new stable $\beta$ type burn resistant titanium alloy, and has been also designed to reach the service temperature of $873 \mathrm{~K}^{[10]}$. Ti40 alloy possesses good mechanical properties and burn resistance ${ }^{[11,12]}$. However, it is very difficult for cogging of this alloy due to its uneasy deformation, heavy oxidation and easy cracking in the ingot breakdown process. Therefore, researchers are interested in its as-cast, which is the primary coverage of this paper. Additionally, its high temperature oxidation behavior in the temperature range of 923 1323 K has been researched by Zhao et al. ${ }^{[13]}$ The fracture behaviors of $\beta \mathrm{Ti}$ during hot working are described well in the Refs. [14-16]. Moreover, the fracture behavior and damage mechanism of Ti40 have been also investigated in the prophase work $^{[17,18]}$. But the influence of deformation parameters on fracture mechanism of Ti40 titanium alloy is not yet analyzed in-depth. Since this alloy is very easy to fracture during cogging and forging, it is imperative to study the effect of deformation parameters on fracture mechanism of Ti40 in order to know the relationship between deformation parameters and fracture mechanism and further improve the ingot cogging and forging technology.

In the present paper, the fracture ways were researched in detail based on the observation of macroscopic fracture specimens and analysis of microstructure. The crack initiation and propagation were determined by the detection of fracture surface using SEM. The objective is to establish the relationship between fracture mechanism and deformation parameters in order to provide some support for the optimization of processing parameters during as-cast Ti40 alloy cogging process.

\section{Experiment}

The chemical composition of Ti40 alloy ingot with a diameter of $350 \mathrm{~mm}$, employed in the present work, is listed in Table 1 . The $\alpha+\beta / \beta$ phase transus temperature of this alloy is calculated to be approximate $737.9 \mathrm{~K}$ based on the formula of phase transformation temperature: $T_{\alpha+\beta / \beta}=1158 \mathrm{~K}+\Sigma$ (element content $(w t \%) \times$ effect of element on phase transformation
Table 1 Chemical composition of Ti40 alloy ingot ( $w t \%)$

\begin{tabular}{ccccccc}
\hline $\mathrm{V}$ & $\mathrm{Cr}$ & $\mathrm{Si}$ & $\mathrm{N}$ & $\mathrm{O}$ & $\mathrm{H}$ & $\mathrm{Ti}$ \\
\hline 25.47 & 14.85 & 0.32 & 0.008 & 0.07 & 0.002 & Balance \\
\hline
\end{tabular}

temperature $)^{[19]}$. The initial microstructure of this alloy consists of a single $\beta$ phase with thin grain boundary and average grain size approximately $0.6 \mathrm{~mm}$, as shown in Fig.1. Cylindrical specimens with $10 \mathrm{~mm}$ in diameter and $15 \mathrm{~mm}$ in length were machined from the ingot for hot compression tests.

In order to study the damage and fracture mechanism of as-cast Ti40 alloy, the hot compression tests were carried out at the deformation temperatures of 1123, 1173, 1223, 1273, $1323,1373 \mathrm{~K}$, strain rates of $0.01,0.1,1,10 \mathrm{~s}^{-1}$ and height reduction of $70 \%$ on a Gleeble $1500 \mathrm{D}$ thermal simulator. The $\mathrm{Pt}-\mathrm{Rh}$ thermocouples were welded in the middle surface of the specimens to measure the actual temperature. The lubrication was done with graphite powder and was made effective by coating it on the top surface and bottom of specimen; tantalum chip of $0.1 \mathrm{~mm}$ was placed between die and specimen to prevent cementation. Specimens were heated to the corresponding test temperatures at $283 \mathrm{~K} / \mathrm{s}$, kept for $5 \mathrm{~min}$ and then deformed up to $70 \%$ under constant strain rate. The specimens were cooled in the air after hot compression in order to preserve the high-temperature fracture morphologies. The true stress-strain curves were recorded automatically in the hot compression process.

\section{Results and Discussion}

\subsection{Analysis of flow curves and fracture modes}

The flow curves at the strain rate of $10 \mathrm{~s}^{-1}$ and various deformation temperatures of 1123 1373 K are shown in Fig.2. It can be seen from Fig. 2 that the flow stress increases with the increasing strain rates and decreasing deformation temperatures. Specially, it is noticed that at $1123 \mathrm{~K}$, the flow stress drops rapidly with the increase of strain, which is attributed to the material failure due to the occurrence of serious $45^{\circ}$ shear fracture in hot compression of as-cast Ti40 alloy, as shown in Fig.3. Obviously, the $45^{\circ}$ shear fracture is transgranular. Besides, all of curves in Fig.2 display noticeable oscillation which might be an indication of flow instability, cracking or dynamic recrystallization ${ }^{[20,21]}$. In order to make the fracture

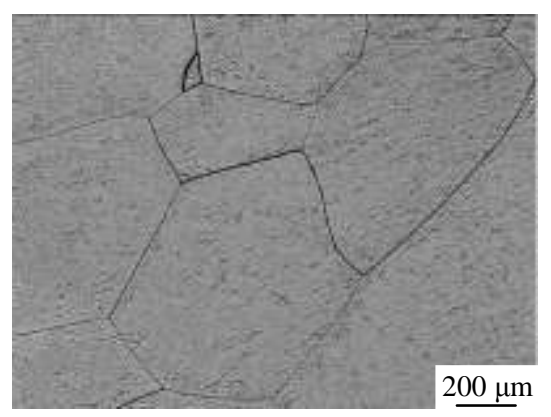

Fig.1 Microstructure of the as-received as-cast Ti40 alloy 


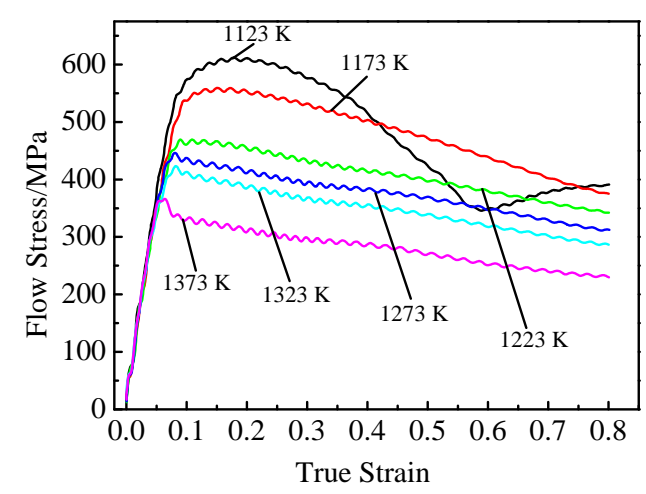

Fig.2 Typical flow curves at the strain rate of $10 \mathrm{~s}^{-1}$ and various deformation temperatures of $1123 \sim 1373 \mathrm{~K}$

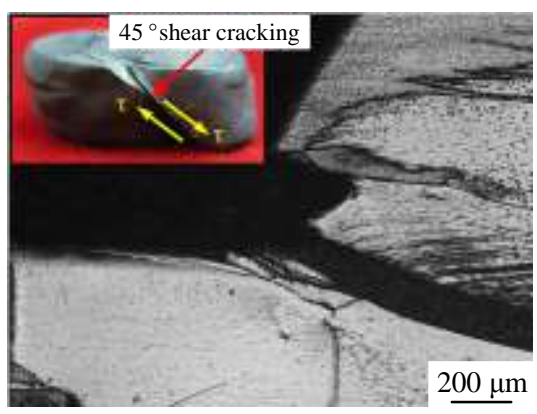

Fig.3 $45^{\circ}$ shear transgranular fracture at $1123 \mathrm{~K}, 10 \mathrm{~s}^{-1}$

reason more clear, the fracture modes of as-cast Ti40 alloy during high-temperature deformation will be analyzed next.

The main fracture modes of as-cast Ti40 alloy under different deformation conditions can be divided into three types, i.e. $45^{\circ}$ shear fracture and longitudinal cracking on free-surface, as well as inner cracking, which occurs at $1123 \mathrm{~K}$, $10 \mathrm{~s}^{-1}, 1273 \mathrm{~K}, 0.1 \mathrm{~s}^{-1}$ and $1173 \sim 1223 \mathrm{~K}, 10 \mathrm{~s}^{-1}$ respectively, as shown in Fig. 3 and 4. The shear bands initiate, at the center of specimen and propagate along the $45^{\circ}$ shear stress direction. With the increasing reduction, the shear bands evolve into cracks across the whole specimen and eventually a $45^{\circ}$ shear fracture is developed, as it can be seen from Fig.3. So the shear stress is the reason for $45^{\circ}$ shear transgranular cracking. From Fig. $4 a$ and $4 b$, it can be seen that the longitudinal fracture occurs on the free-surface, and the crack starts at the triple boundary junctions, and then the crack propagates along the gain boundaries due to the circumferential tensile stress, and finally the longitudinal intergranular cracking occurs. Generally, the cracking consists of two vital processes i.e. crack nucleation and crack propagation. For the as-cast Ti40 alloy, it can be seen from Fig.4c and 4d, the inner cracks near the adiabatic shear bands are observed and the cracks propagation direction is consistent with shear bands. Thus the inner intergranular cracking at the high strain rate of $10 \mathrm{~s}^{-1}$ might be the result of stress concentration at the triple boundary junctions under the shear stress. This is in good agreement with that reported in Ref. [22].

\subsection{Effect of deformation temperatures on fracture behavior}

The damage and fracture conditions of as-cast Ti40 alloy at the high strain rate of $10 \mathrm{~s}^{-1}$ and different deformation temperatures are shown in Fig.5. It can be seen from Fig.5a, $5 \mathrm{~b}$ $5 \mathrm{~d}, 5 \mathrm{e}, 5 \mathrm{~g}$, and $5 \mathrm{~h}$ that the fracture modes change from $45^{\circ}$ transgranular cracking into intergranular cracking with the

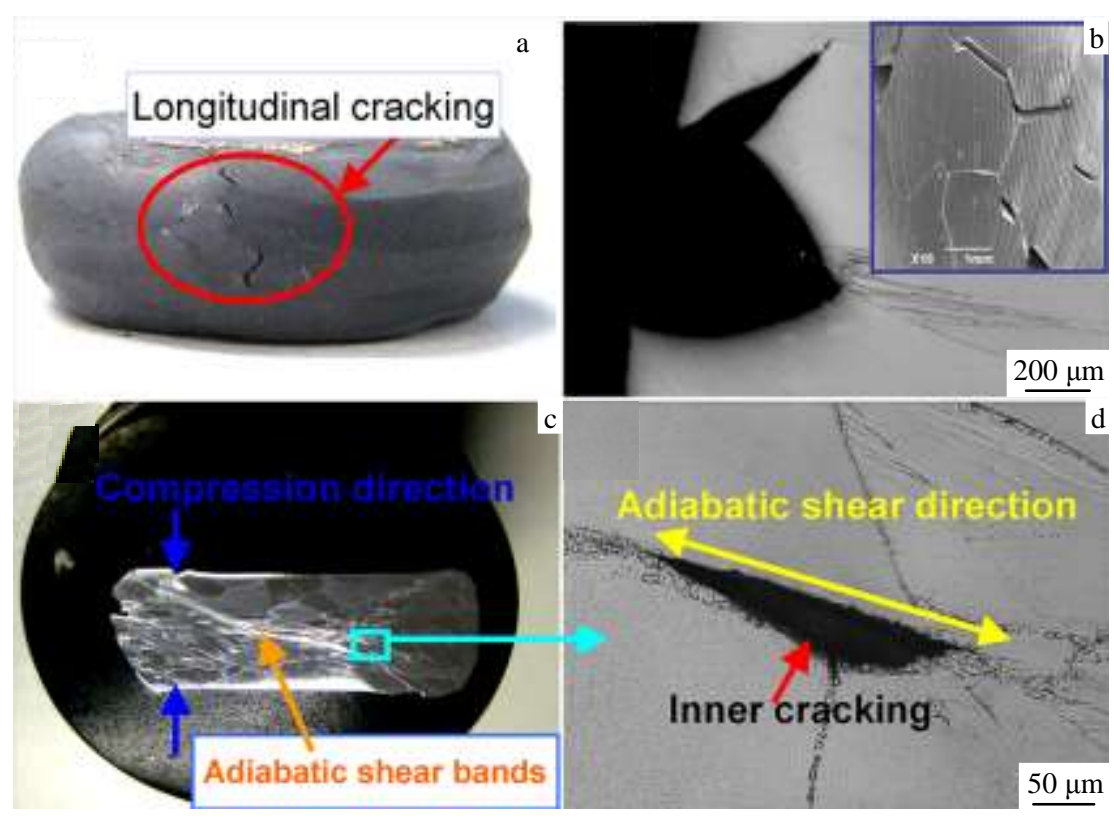

Fig.4 Fracture modes of as-cast Ti40 alloy: (a) macro-longitudinal cracking at $1273 \mathrm{~K}, 0.1 \mathrm{~s}^{-1}$, (b) longitudinal intergranular cracking at $1123 \mathrm{~K}$, $1 \mathrm{~s}^{-1}$ and (c, d) inner intergranular cracking at $1173 \sim 1223 \mathrm{~K}, 10 \mathrm{~s}^{-1}$ 


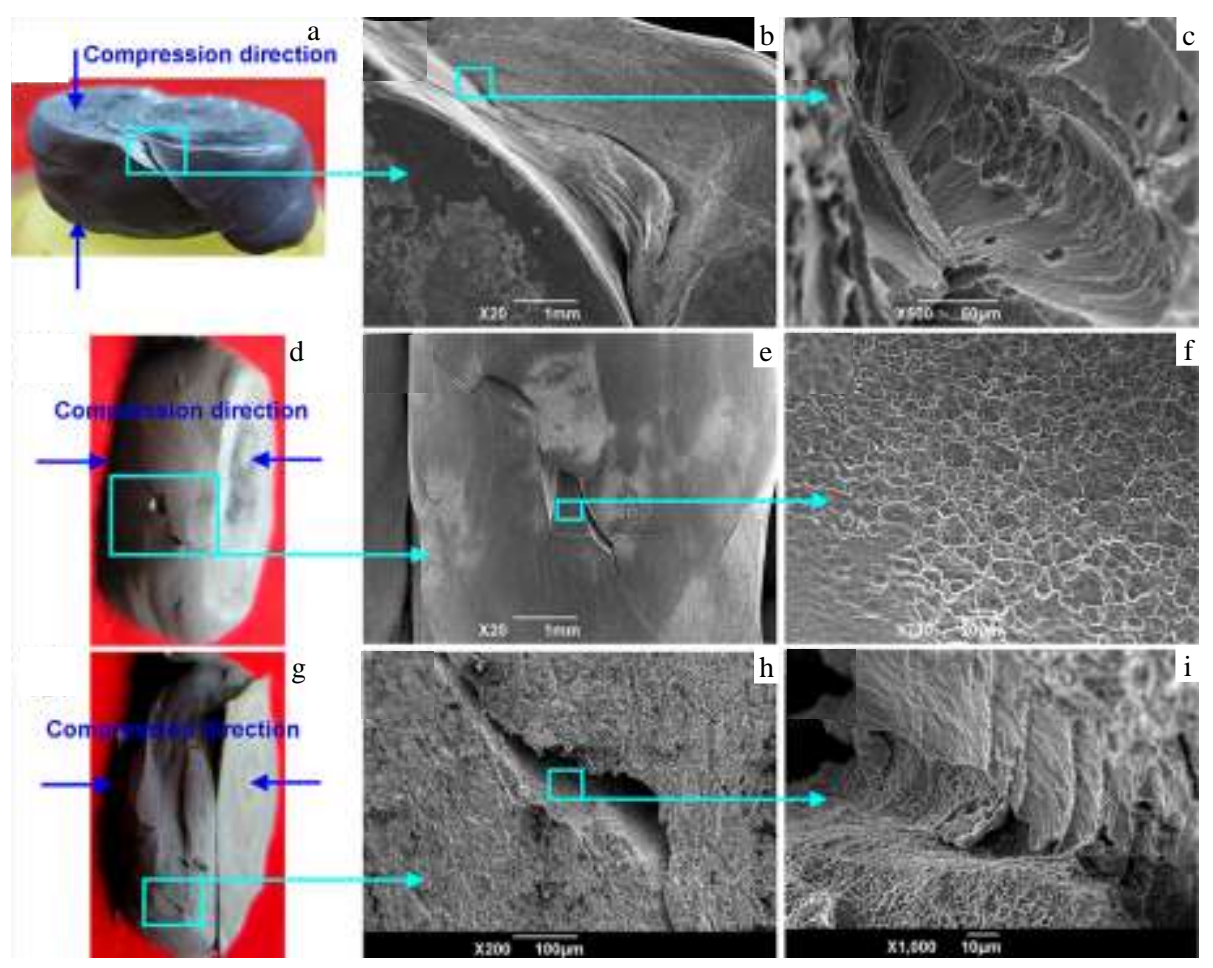

Fig.5 Macroscopic and SEM fracture images of compression specimens at $10 \mathrm{~s}^{-1}$ : (a, b, c) $1123 \mathrm{~K}$, (d, e, f) $1273 \mathrm{~K}$ and (g, h, i) $1373 \mathrm{~K}$

increasing deformation temperature. It is seen that from Fig.5c that at low temperature of $1123 \mathrm{~K}$, the transgranular cleavage brittle fracture accounts for most of the fracture surface, on which a small quantity of dimples are observed, indicating the mixed brittle fracture. The cleavage brittle fracture region is shown in terms of typical "ripple waves" tear ridges; meanwhile this region also consists of small dimples. At the middle temperature of $1273 \mathrm{~K}$ as shown in Fig.5f, it can be seen that the ductile fracture surface is covered with small and shallow dimples, presenting certain plasticity. Once it reaches $1373 \mathrm{~K}$ (Fig.5i), a large number of small dimples on the fracture surface are observed, which demonstrates that the ductile fracture occurs at high temperature, and the plasticity of as-cast Ti40 alloy has improved with the continuously raised temperature. However, through the macroscopic observation of specimens (Fig.5g, 5h), it is found that at the higher temperature $(\geq 1323 \mathrm{~K})$ the free-surface cracking is more serious. This is because of the more obvious surface oxidation with the increasing temperature, which further induces more oxidation microcracks.

\subsection{Effect of strain rates on fracture behavior}

The damage and fracture mechanism of as-cast Ti40 alloy at low strain rates of 0.1 and $1 \mathrm{~s}^{-1}$ as well as deformation temperature of $1273 \mathrm{~K}$ is shown in Fig.6. It is seen from Fig.6b and $6 \mathrm{e}$ that the crack starts on the triple boundary junctions, and then the crack propagates along the gain boundaries under the circumferential tensile stress, and finally the longitudinal cracking occurs. Under this circumstance, the stress of crack tip is relaxed by the plastic deformation of $\beta$ phase. Macroscopically, the cracking degree increases with the increasing strain rate (Fig.6a and Fig.5d). Moreover, it can be known that the dimples like "droplets" show the feature of directivity due to the influence of circumferential tensile stress on crack propagation direction. Furthermore, the fracture surface is covered with a large amount of dimples which indicates that the fracture mode is ductile fracture (Fig. $6 \mathrm{c}$ and 6f). The plastic deformation and ductility fracture of $\beta$ phase lead to the formation of dimples, as shown in Fig.6c and $6 \mathrm{f}$. But at the higher strain rate of $10 \mathrm{~s}^{-1}$ (Fig.5e and 5f), this alloy presents the brittle fracture, which indicates the poor ductility of specimens deformed at high strain rate. With the increasing strain rate, the expansion velocity of cracks increases, which promotes the fracture mode of this alloy to transform from ductile to brittle, causing a significant decline in ductility.

\subsection{Discussion on damage mechanism and fracture reason}

In general, the basic fracture modes of crack extension include opening (mode I), in-plane shear (mode II) and out-of-plane tearing (mode III). Mode I corresponds to normal separation of the crack faces under the action of tensile stresses, as shown in Fig.6. This indicates that at low strain rates, the fracture of as-cast Ti40 alloy is opening type. The difference between mode II and mode III is the shear direction, which is normal to the front face of crack in mode II whereas is parallel to the front face of crack in mode III. In reality, the crack on a cracked body can be presented in any one of the three modes, or a combination of three modes. For instance, in 

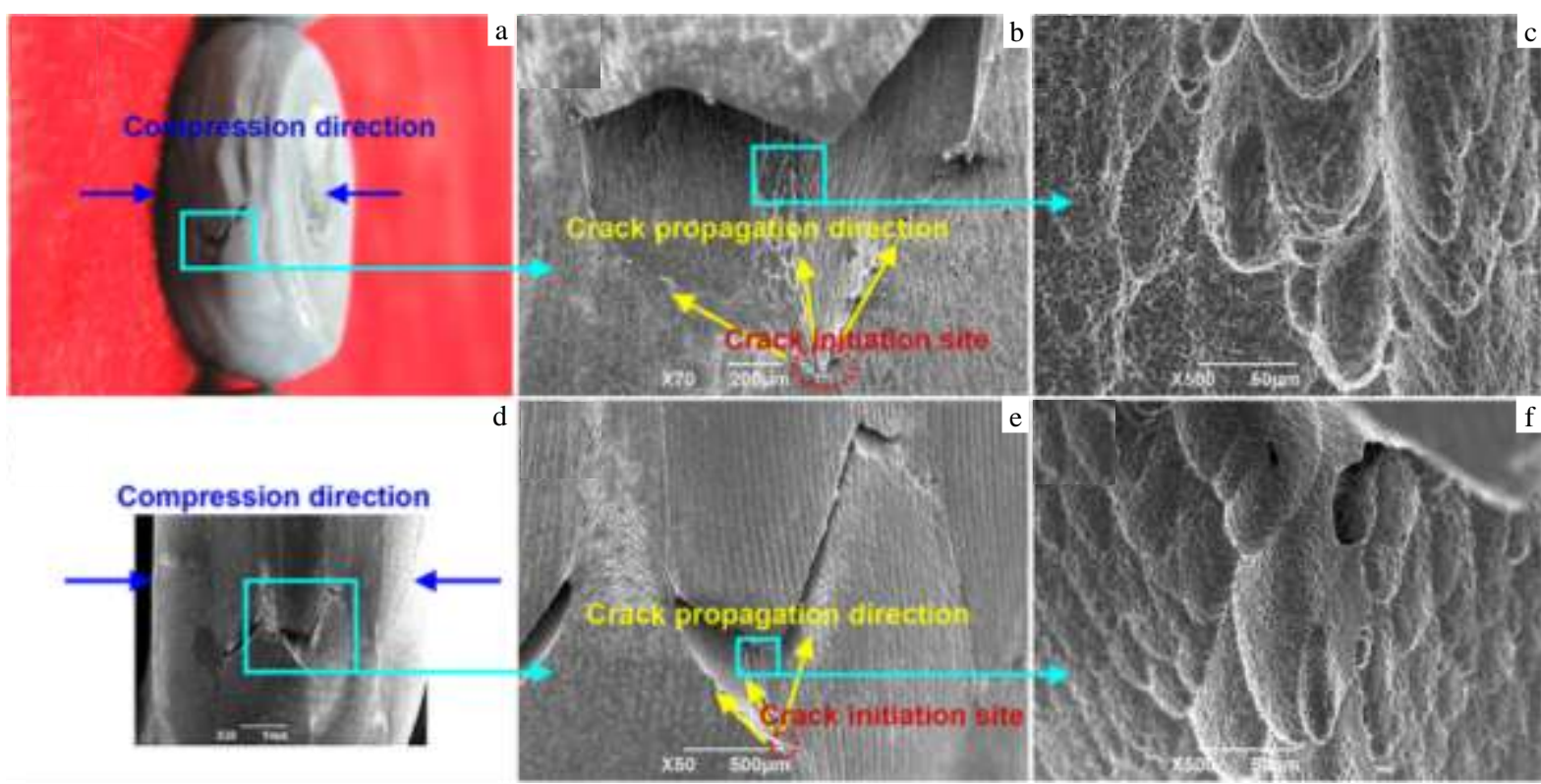

Fig.6 Macroscopic and SEM fracture graphs of compression specimens at $1273 \mathrm{~K}:(\mathrm{a}, \mathrm{b}, \mathrm{c}) 0.1 \mathrm{~s}^{-1}$ and (d, e, f) $1 \mathrm{~s}^{-1}$

Fig.5e, the fracture of specimen is the result of mode I and mode II. Gross and Seelig ${ }^{[23]}$ also considered that the cracks are kinked and afterwards grown up in a certain direction of overall compression under the combination of mode II and mode I. Obviously, the macroscopic fracture behavior of as-cast Ti40 alloy is nonlinear due to the increasing damage, and it is found that the instability leads to the localization of damage in the course of deformation. Gross and Seelig ${ }^{\text {[23] }}$ pointed out that this localization often took place in form of shear bands which originated from the growth and coalescence of shear cracks and were inclined at a certain angle to the overall compressive load. This is in good agreement with the occurrence of $45^{\circ}$ shear cracking in Fig.5a of this paper.

Through the above analysis, it can be concluded that the processing parameters such as deformation temperature and strain rate significantly affect the compression fracture behavior of as-cast Ti40 alloy, as shown in Fig.7. Compared with bimodal, tri-modal or lamellar microstructures, the single $\beta$ phase, due to its good plasticity, is subjected to intense plastic deformation before fracture (Fig.5b), and then the white tearing ridge is formed rather than the smooth facets (Fig.5c). So at higher strain rate and lower temperature, the crack prefers to cross the $\beta$ phase due to its lower deformation stress, as illustrated in Fig.7a. Fig.7b shows the macro- and micro-cracking patterns and the deformation conditions. It can be seen that the deformation conditions when cracking patterns occur both are really consistent with longitudinal intergranular cracking on free-surface and inner intergranular cracking of as-cast Ti40 alloy. Because the grain boundaries are weakened, the voids and cracks are preferentially formed at the grain boundaries, and expanded along them. In view of the weakness of grain boundaries for as-cast Ti40 alloy, the plasma sprayed pure titanium on billet surface and sheathed extrusion technique are applied for preventing the oxidation of the workpiece during heating and reducing the extra tensile stress further decreases the oxidation-induced fracture. Conversely, at lower strain rate and higher temperature, the plastic deformation and ductility fracture of $\beta$ phase lead to the formation of dimples (Fig.6), and the crack tend to initiate along the grain boundaries (shown in Fig.7c) than $\beta$ phase, because the grievous high-temperature oxidation causes the weaker grain boundaries. Consequently, the oxidation should be responsible for the decrease in ductility of as-cast Ti40 alloy. Zhao et al. ${ }^{[13]}$ researched the oxidation behavior of Ti40 alloy, and pointed out three reasons for this alloy's fast oxidation, i.e. protective $\mathrm{Al}_{2} \mathrm{O}_{3}$ and $\mathrm{Cr}_{2} \mathrm{O}_{3}$ oxides could not be formed, porous oxides selectively formed from $\mathrm{Ti}$ and $\mathrm{V}$ such as porous $\mathrm{TiO}_{2}$ and evaporated $\mathrm{V}_{2} \mathrm{O}_{5}$, and the vaporization of $\mathrm{V}_{2} \mathrm{O}_{5}$ on the gain boundaries. The melting point of $\mathrm{V}_{2} \mathrm{O}_{5}$ happened is $948 \mathrm{~K}$ and it will evaporate over $973 \mathrm{~K}$. Coupled with the microstructure observation in the present paper, it can be inferred that the vaporization of $\mathrm{V}_{2} \mathrm{O}_{5}$ causes voids and makes it become one of main reasons for Ti40 fast oxidation fracture in hot compression process. Ghazisaeidi and Trinkle ${ }^{[24]}$ investigated the interactions of oxygen with (10 $\overline{1} 2$ ) twin boundaries and (10 $\overline{1} 0)$ prism plane stacking faults, and showed that the oxygen atom induced significant relaxations on its nearest neighbor $\mathrm{Ti}$ atoms, thereby creating new interstitial sites at and around the twin boundary. Joost et al. ${ }^{[25]}$ also interrogated the behavior of oxygen $(\mathrm{O})$ interstitials near a $(10 \overline{1} 2)$ twin boundary using a combination of density functional theory and modified embedded atom method calculations in alpha-titanium. Therefore, the formation of 


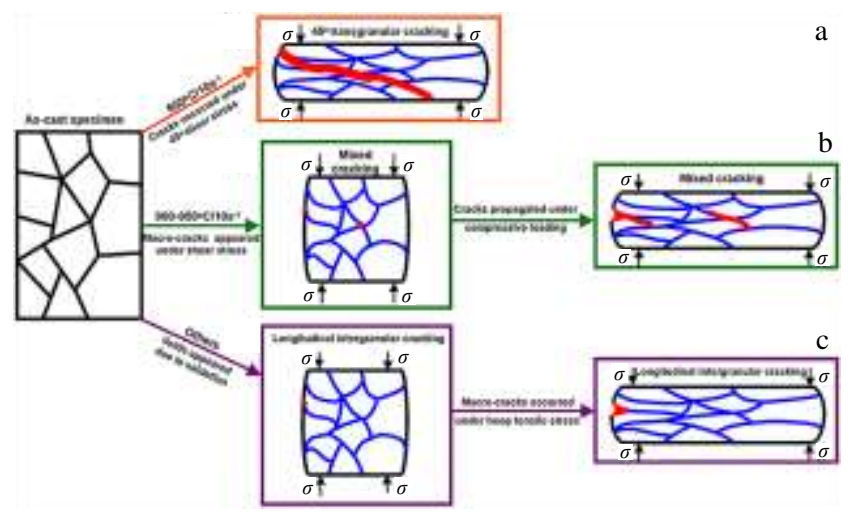

Fig.7 Illustration of micro-damage mechanisms for particular deformation conditions: (a) $45^{\circ}$ shear transgranular fracture on free-surface under $45^{\circ}$ shear stress; (b) internal microcracking due to ductile void growth and (c) longitudinal intergranular fracture on free-surface due to oxidation and hoop tensile stress

porous Ti-based oxides along the gain boundaries or ingress of interstitials $\mathrm{O}$ into grain boundaries exposed to the surfaces might cause the weakening gain boundaries. Zhang and $\mathrm{Cai}^{[26]}$ illustrated the micro-damage mechanisms for particular deformation conditions and distinguished several fracture modes based on nucleation of cavities and void growth; during the micro-cracking stage due to ductile void growth, damage was generated in second phases at both grain boundaries, and micro-cracking occurred at hot forming with high strain rates. This is also observed in the present paper (Figs. 5 and 6). With regard to the problem that fracture is easy to occur at high strain rate, the low-speed forming equipment should be used for Ti40 ingot cogging.

\section{Conclusions}

1) $45^{\circ}$ shear fracture occurring at $1123 \mathrm{~K}, 10 \mathrm{~s}^{-1}$ is transgranular cracking, which is caused by local temperature rise and shear stress. The longitudinal fracture occurring on free-surface is intergranular cracking, which is the combination result of the vaporization of oxide, weakening of grain boundaries and function of hoop tensile stress. The inner cracking at the triple boundary junctions is also intergranular cracking, which is induced by the microvoids near the adiabatic shear bands.

2) The effect of deformation temperature on the damage and fracture mechanism of as-cast Ti40 alloy is significant. The plasticity increases with the increasing deformation temperature. At low temperature of $1123 \mathrm{~K}$ the transgranular cleavage brittle fracture accounts for most of the fracture, at middle temperature of $1273 \mathrm{~K}$ the ductile fracture occurs on the fracture; surface covered with small and shallow dimples, at high temperature of $1373 \mathrm{~K}$ a large number of small dimples; on the fracture surface are examined.
3) At low strain rate of $0.01 \mathrm{~s}^{-1}$, the fracture does not occur. On the contrary, at higher strain rates the fracture of as-cast Ti40 alloy is serious, and the fracture degree increases and plasticity decreases with the increasing strain rate. At the strain rates of 0.1 and $1 \mathrm{~s}^{-1}$, the fracture surface is covered with a large amount of dimples indicating that the fracture mode is ductile fracture, while at the high strain rate of $10 \mathrm{~s}^{-1}$, the fracture surface shows brittle fracture feature.

\section{References}

1 Gouveia B P P A, Rodrigues J M C, Martins P A F. International Journal of Mechanical Sciences[J], 1996, 38: 361

2 Kiran R, Khandelwal K. Engineering Fracture Mechanics[J], 2015, 145: 15

3 Katani S, Madadi F, Atapour M et al. Materials Design[J], 2013, 49: 1016

4 Boutarek N, Saïdi D, Acheheb M A et al. Material Characteristic[J], 2008, 59: 951

5 Semiatin S L, Goetz R L, Shell E B et al. Metallurgical and Materials Transactions A[J], 1999, 30: 1411

6 Calcagnotto M, Adachi Y, Ponge D et al. Acta Materialia[J], 2011, 59: 658

7 Williams J C, Starke Jr E A. Acta Materialia[J], 2003, 51: 5775

8 Prasad Y V R K, Seshacharyulu T. Materials Science and Engineering $A[\mathrm{~J}], 1998,243: 82$

9 Palumbo G, Brandizzi M. Materials Design[J], 2012, 40: 43

10 Zhao Y Q, Zhao X M, Zhu K Y et al. Rare Metal Materials and Engineering [J], 1996, 25: 1 (in Chinese)

11 Zhao Y Q, Zhou L, Deng J. Materials Science and Engineering $A[\mathrm{~J}], 1999,267: 167$

12 Zhao Y Q, Zhou L, Deng J. Rare Metal Materials and Engineering[J], 1999, 28(2): 77 (in Chinese)

13 Zhao Y Q, Qu H L, Zhu K Y et al. Materials Science and Engineering $A[\mathrm{~J}], 2001,316: 211$

14 Semiatin S L, Seetharaman V, Weiss I. Materials Science and Engineering $A[\mathrm{~J}], 1998,243: 1$

15 Weiss I, Semiatin S L. Materials Science and Engineering A[J], 1998, 243: 46

16 Motyka M, Kubiak K, Sieniawski J et al. In Nurul Amin A K M ed. Titanium Alloys-Towards Achieving Enhanced Properties for Diversified Applications[M]. Munich: In Tech, 2012: 87

17 Zhu Y C, Zeng W D, Peng W W et al. Rare Metal Materials and Engineering[J], 2013, 42(10): 2088 (in Chinese)

18 Zhu Y C, Zeng W D, Zhao Y Q et al. Advanced Materials Research[J], 2013, 750-752: 721

19 Editing Team of Rare Metal Materials Processing Handbook. Rare Metal Materials Processing Handbook[M]. Beijing: Metallurgical Industry Press, 1984: 1

20 Seshacharyulu T, Medeiros S C, Frazier W G et al. Materials Science and Engineering A[J], 2000, 284: 184

21 Seshacharyulu T, Medeiros S C, Frazier W G et al. Materials Science and Engineering A[J], 2002, 325: 112

22 Shi D K. Fundamentals of Materials Science[M]. Beijing: China 
Machine Press, 1999: 10

23 Gross D, Seelig T. Fracture Mechanics with an Introduction to Micromechanics[M]. Berlin Heidelberg, Netherlands: SpringerVerlag, 2006: 1

24 Ghazisaeidi M, Trinkle D R. Acta Materialia[J], 2014, 76: 82
25 Joost W J, Ankem S, Kuklja M M. Acta Materialia[J], 2016, 105: 44

26 Zhang W H, Cai Y Q. Continuum Damage Mechanics and Numerical Applications[M]. Hangzhou: Zhejiang University Press, 1995: 21

\title{
变形参数对 Ti40 钛合金开裂机制的影响
}

\author{
朱艳春 ${ }^{1,2}$, 曾卫东 ${ }^{2}$, 赵永庆 $^{3}$
}

(1. 太原科技大学 太原重型机械装备协同创新中心，山西 太原 030024)

(2. 西北工业大学 凝固技术国家重点实验室，陕西 西安 710072)

(3. 西北有色金属研究院, 陕西 西安 710016)

摘 要: 材料成形过程中, 一个备受关注的问题是能否实现在不发生开裂的基础上达到要求的变形。本实验基于热压缩实验（变形温度 为 1123 1373 K, 应变速率为 $0.01 \sim 10 \mathrm{~s}^{-1}$, 变形量为 70\%) 获得的开裂样本, 证实了铸态 Ti40 合金的主要开裂模式为 $45^{\circ}$ 剪切开裂、自 由表面纵向开裂和内部三叉晶界沿晶开裂。借助 SEM 重点分析了变形参数对开裂机制的影响规律, 发现在低温 $1123 \mathrm{~K}$ 变形时, 主要是 穿晶解理脆性断裂, $1273 \mathrm{~K}$ 变形时, 转变为韧性断裂, 高温 $1373 \mathrm{~K}$ 变形时, 大量的小韧窝被观察到; 应变速率对铸态 Ti40 合金的开裂 行为也具有重要影响, 在低应变速率 $0.01 \mathrm{~s}^{-1}$ 变形时, 样本没有发生开裂, 在 0.1 和 $1 \mathrm{~s}^{-1}$ 变形时, 在开裂表面观察到大量的㓞窝, 属于㓞 性开裂, 在高应变速率 $10 \mathrm{~s}^{-1}$ 变形时, 开裂表面呈现脆性开裂特征。最后深入探讨了铸态 Ti40 合金的损伤机制和开裂原因, 绘制了铸态 Ti40 合金的开裂原理图。

关键词：Ti40 钛合金; 变形参数; 开裂机制

作者简介: 朱艳春, 女, 1982 年生, 博士, 太原科技大学机械工程学院, 山西 太原 030024, 电话: 0351-6998115, E-mail: 1zlzyc@163.com 